\title{
Fetal cardiac rhabdomyoma as sonographic sign of tuberous sclerosis complex - a diagnosis not to be missed.
}

Dan Boitor Borza ${ }^{1}$, Roxana Popa Stanila ${ }^{2}$, Gabriela Zaharie ${ }^{1}$, Monica Hasmasanu ${ }^{1}$, and Daniel Muresan ${ }^{1}$

${ }^{1}$ UMF Iuliu Haţieganu Cluj-Napoca

${ }^{2}$ Affiliation not available

September 25, 2021

\begin{abstract}
Fetal cardiac rhabdomyoma should trigger the awareness of potential coexisting tuberous sclerosis complex that can lead to a poor neurological outcome. This condition is not only uncommon but can be easily unrecognized prenatally in the absence of a meticulous neurosonogram and MRI. We emphasize that careful consideration of all prenatal facilities is needed to confirm the diagnosis of tuberous sclerosis complex as early as possible during pregnancy. Key words: cardiac rhabdomyoma; tuberous sclerosis; prenatal diagnosis
\end{abstract}

\section{Hosted file}

Fetal cardiac rhabdomyoma as sonographic sign of tuberous sclerosis complex - a diagnosis not to be mis available at https://authorea.com/users/437844/articles/539200-fetal-cardiac-rhabdomyoma-assonographic-sign-of-tuberous-sclerosis-complex-a-diagnosis-not-to-be-missed

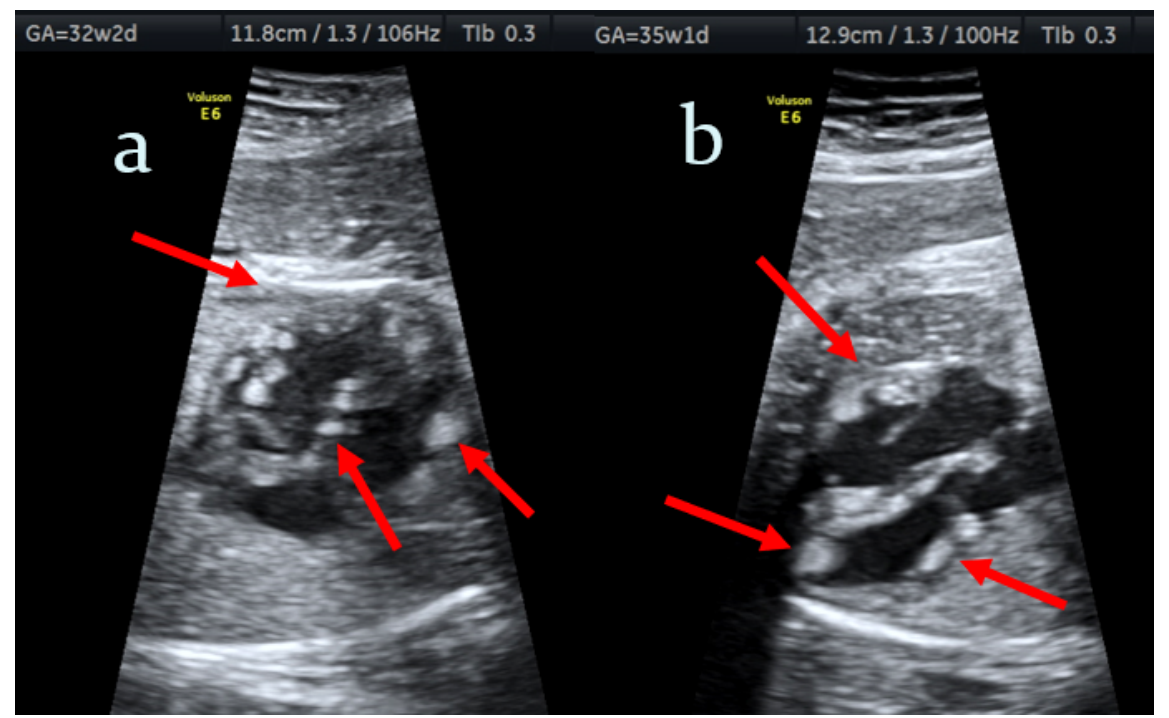



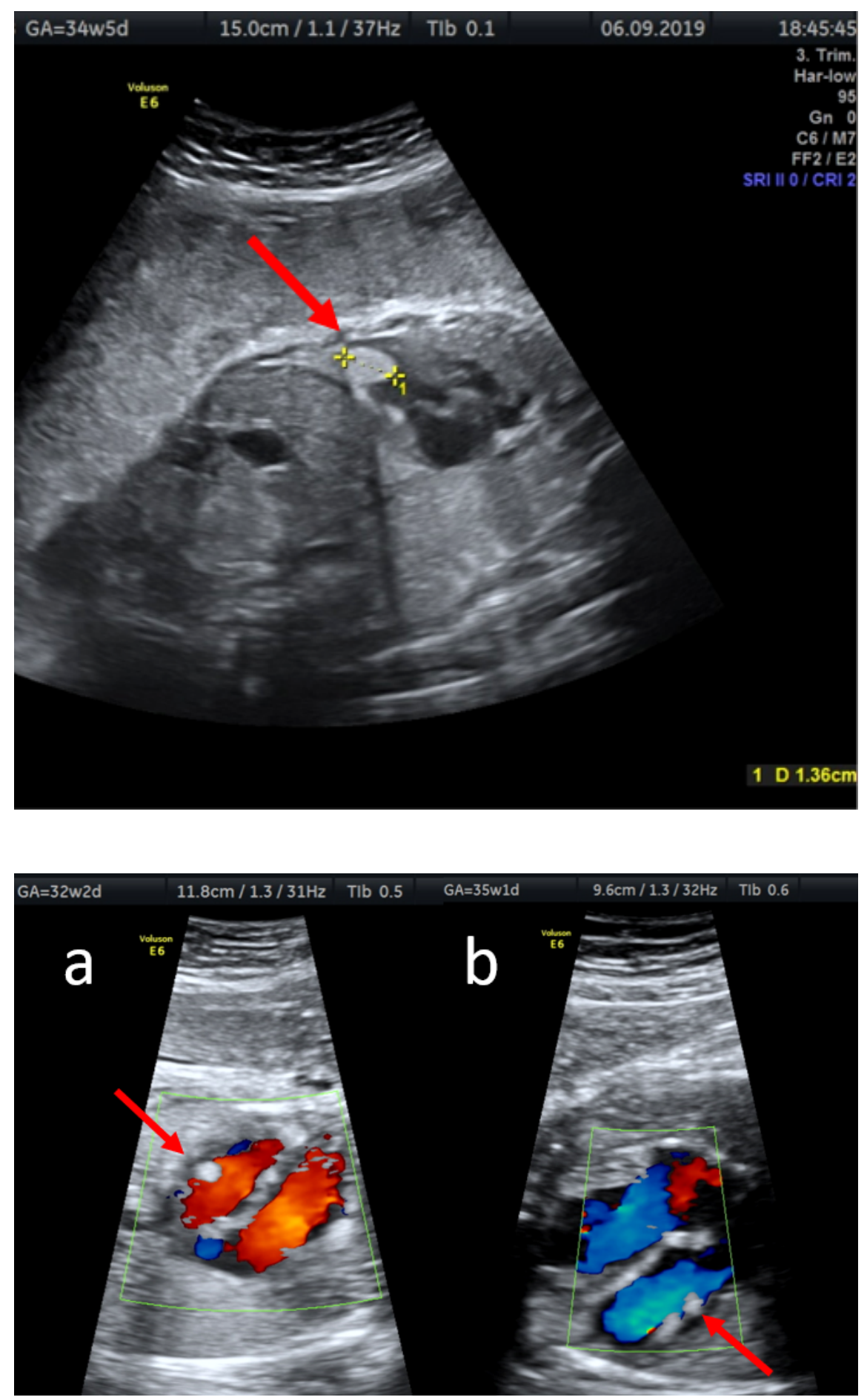


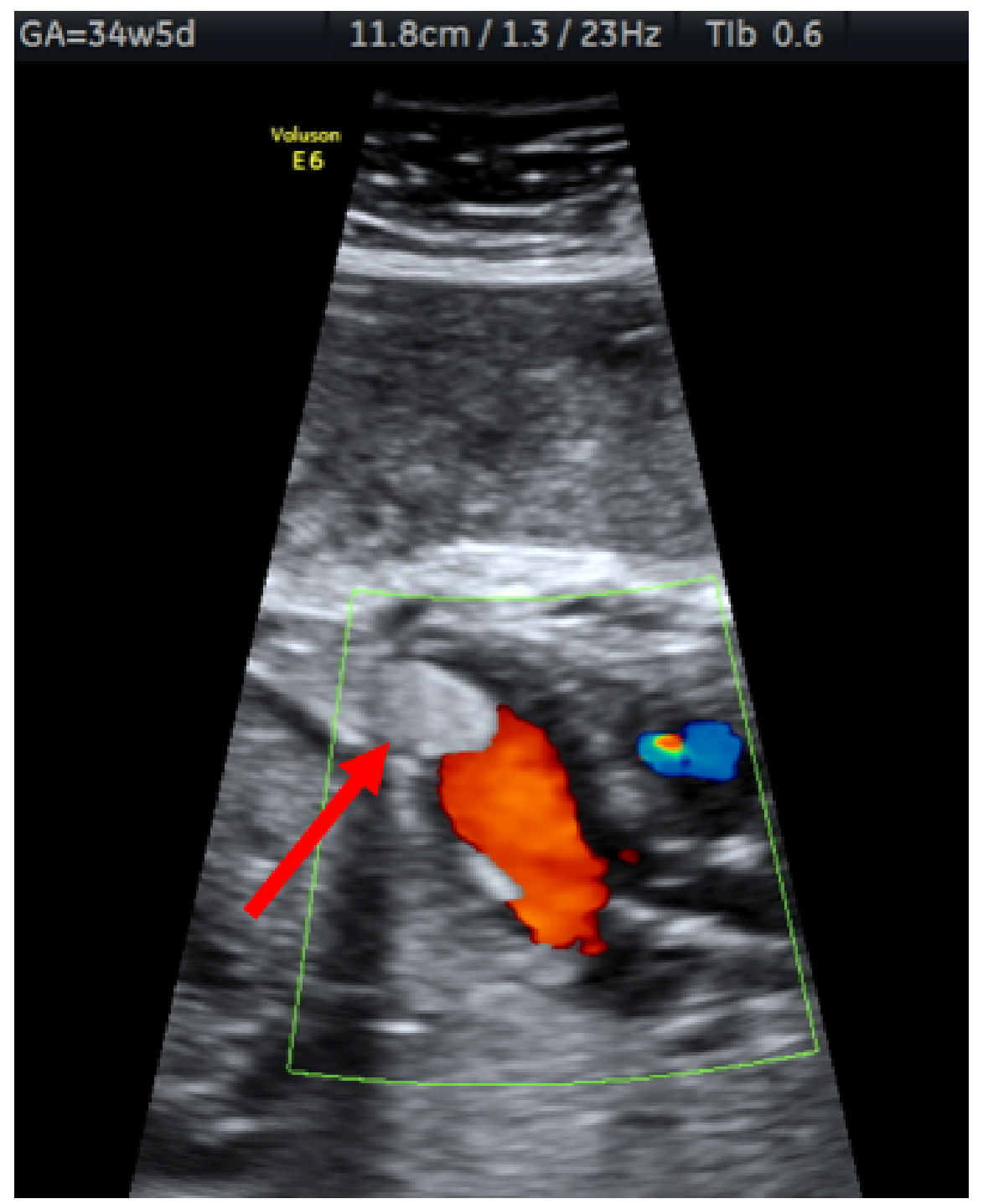



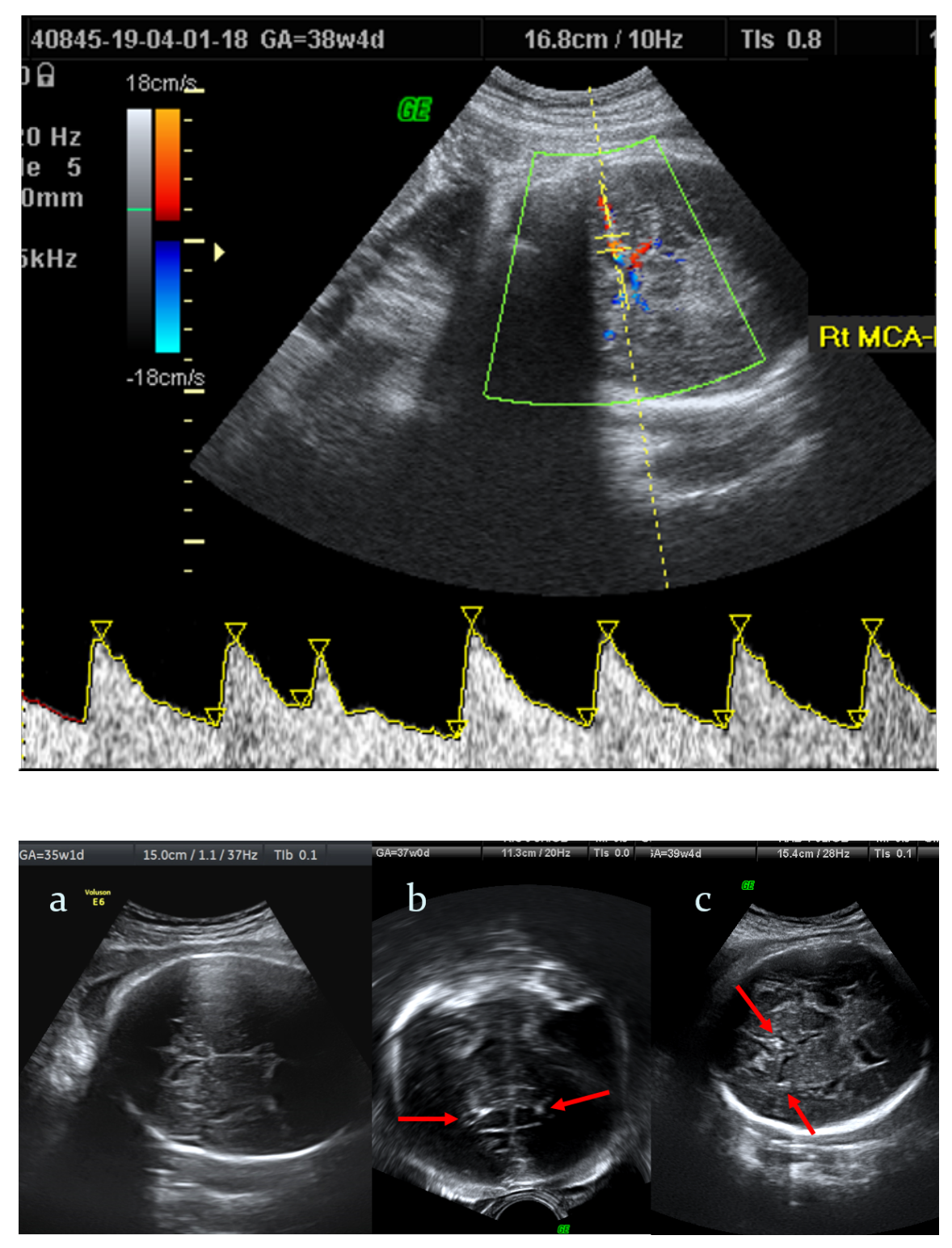

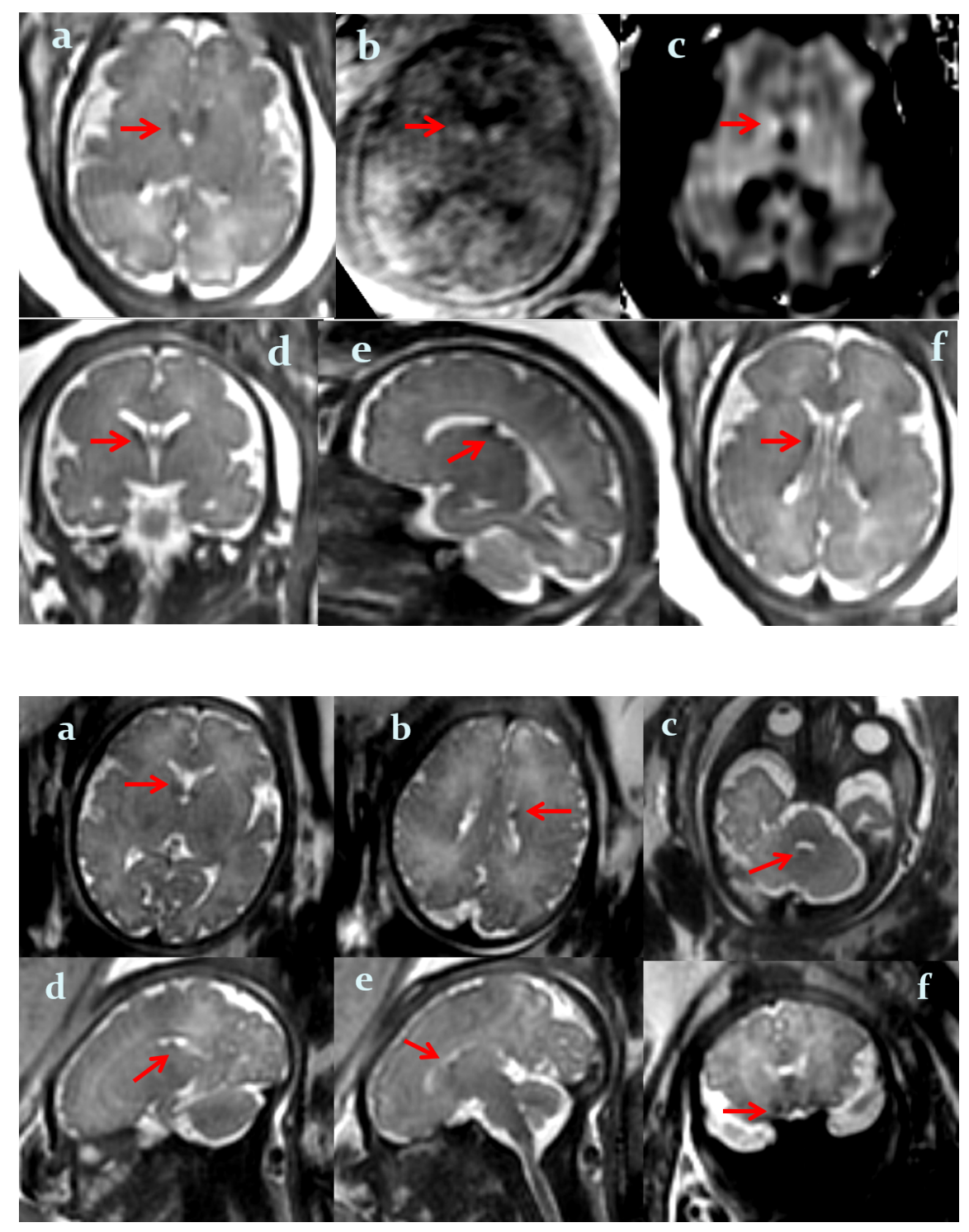


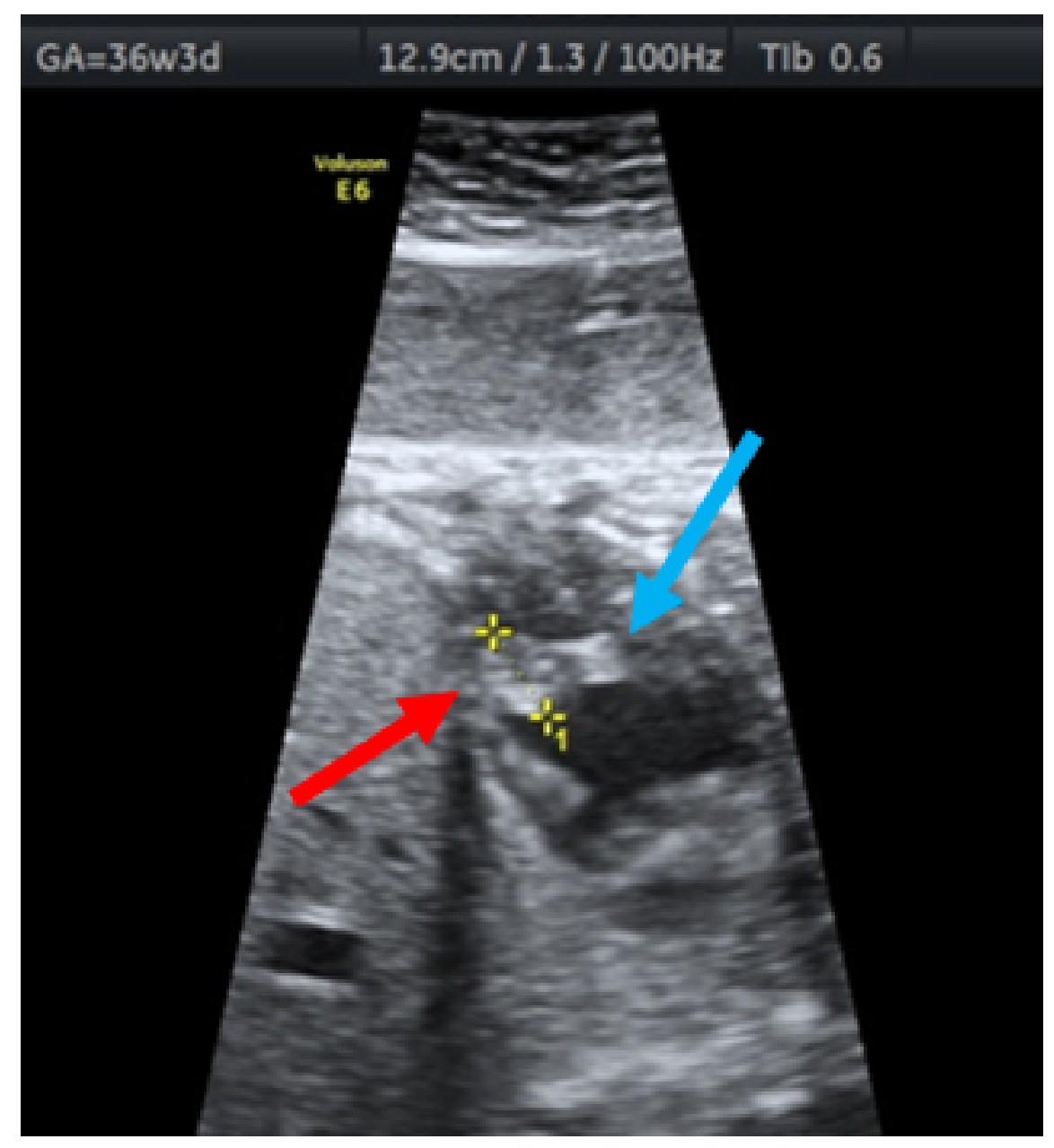

